\title{
Single Shot Epidural Injection for Cervical and Lumbosaccral Radiculopathies: A Preliminary Study
}

The Pain Clinic, Doon Nursing Home, *Himalayan Institute of Medical Sciences, Swami Ram Nagar, Dehradun, India

Digambar Prasad Nawani, MD, Sanjay Agrawal, MD*, and Veena Asthana, MD*

\section{Background:}

Epidural steroid injection is an established treatment modality for intervertebral disc prolapse leading to radiculopathy. In cases where two levels of radiculopathy are present, two separate injections are warranted. Herein, we present our experience of management of such cases with a single epidural injection of local anaesthetic, tramadol and methylprednisolone, and table tilt for management of both radiculopathies.

\section{Methods:}

50 patients of either sex aged between 35-65 years presenting with features of cervical and lumbar radiculopathic pain were included and were subjected to single lumbar epidural injection of local anaesthetic, tramadol and methylprednisolone, in the lateral position. The table was then tilted in the trendelberg position with a tilt of 25 degrees, and patients were maintained for 10 minutes before being turned supine. All patients were administered 3 such injections with an interval of 2 weeks between subsequent injections, and pain relief was assessed with a visual analogue scale. Immediate complications after the block were assessed.

\section{Results:}

Immediate and post procedural complications observed were nausea and vomiting (20\%), painful injection site (4\%), hypotension (10\%) and high block (4\%). Pain relief was assessed after the three injections by three grades: $37(74 \%)$ had complete resolution of symptoms; 18\% had partial relief and $8 \%$ did not benefit from the procedure.

\section{Conclusions:}

This technique may be used as an alternative technique for pain relief in patients with unilateral cervical and lumbar radiculopathies. (Korean J Pain 2010; 23: 254-257)

\section{Key Words:}

cervical, epidural, lumbar, radiculopathy, steroid, tramadol. 


\section{INTRODUCTION}

Spinal neck and low back pain has a prevalence of $65-80 \%$ [1-3]. A common cause is radiculopathy originating from mechanical root compression due to degenerative spine changes such as disc herniation and spondylosis [4]. Numerous authors [5-9] have utilised the technique of local delivery of corticosteroids into the epidural space to reduce inflammation and anaesthetize the affected nerve root, however the effect is variable. In cases of cervical and lumbar disc herniation, utilization of two epidural injections (cervical and lumbar) is warranted. Association of cervical cord damage secondary to epidural steroid injection has been widely reported and associated with significant morbidity. In a closed claim study, most injuries were reported in the setting of chronic pain management [10]. In view of these injuries as well as use of two separate injections, it was hypothesized that administering a large volume of epidural injection and table tilt could be used for pain management in such cases.

This technique was effective in reducing radiculopathy and pain. We present our initial experience of the technique.

\section{MATERIALS AND METHODS}

50 patients of either sex, aged between 35 to 65 years, and classified as ASA I or II presenting to the authors' clinic with features of combined cervical and lumbosaccral radiculopathy of one side were studied. Disc protrusion in all the cases was confirmed with X-rays and MRI. These patients were initially managed conservatively by bed rest, passive physiotherapy; oral NSAIDS and only when there was no pain relief after two weeks of conservative therapywere subjected to epidural steroid injection. The procedure was explained in detail to patients and written informed consent was obtained. On the day of the procedure, patients were shifted to the operating room. Monitoring, such as pulse oximetry, non-invasive blood pressure and electrocardiograph, were established. Patients were preloaded with $500 \mathrm{ml}$ of Ringer Lactate after establishing intravenous access. Epidural injection in all cases was given in the affected lumbar intervertebral space in the lateral position using an 18-gauge Tuohy epidural needle. After locating the epidural space by loss of resistance technique, an injection of $10 \mathrm{ml} 0.25 \%$ bupivacaine
(Anawin, Neon Pharma, India), 100 mg preservative free methylprednisolone (Depopred, Sun Pharma, India) and $100 \mathrm{mg}$ preservative free tramadol (Contramol, Nicholas Piramal, India) were injected into the epidural space. Total volume of the injectate was $15 \mathrm{ml}(10 \mathrm{ml}$ bupivacaine + $2 \mathrm{ml}$ tramadol $(50 \mathrm{mg} / \mathrm{ml})+100 \mathrm{mg}$ depopred $(40 \mathrm{mg} / \mathrm{ml}$ \& $20 \mathrm{mg} / \mathrm{ml})$. Patients were maintained in the lateral position for 10 minutes after which the table was turned into the trendelburg position by tilting it 25 degrees. Patients were maintained in this position for 10 minutes then turned supine and the table turned straight. During this procedure, blood pressure and respiratory depression were carefully monitored. Any fall in blood pressure > $>20 \%$ from baseline was treated with fast infusion of Ringer Lactate and a bolus of injection ephedrine $5 \mathrm{mg}$. After the procedure, patients were moved to the ward and monitored. Two more such injections were given to all the patients with the gap of two weeks between each injection. After each injection, patients were discharged with the advice to continue isometric extension exercise, oral pregabalin $75 \mathrm{mg}$ and NSAIDS for the entire duration of the study. Pain relief was assessed using a visual analogue scale.

\section{RESULTS}

A total of 50 patients were studied (20M : 30F). Mean age of patients was 47.5 years with a range of $35-65$ years (Table 1). C5-6 and L4-5 or L5S1 were the most common affected vertebral levels with radicular pain along the distribution of such nerves. The C56 vertebral level was affected in 10 males and 25 female patients, while C67 level radiculopathy was seen in 10 males and 5 female patients. Associated lumbar pain was seen in the L45 dermatomal level in 15 males and 23 females, while L5S1 radiculopathy was seen in 5 males and 7 females. Mean follow-up of the patients was 4 to 5 years.

Immediate complications from the epidural injection

Table 1. Demographic Profile of Patients

\begin{tabular}{lc}
\hline Total number (n) & 50 \\
\hline Male & 20 \\
Females & 30 \\
Avg. age (Years) & 47.5 \\
Range (Years) & $35-65$ \\
\hline
\end{tabular}


Table 2. Complications of Block

\begin{tabular}{lcc}
\hline \multicolumn{1}{c}{ Complication } & Number & \% of patients \\
\hline Nausea/Vommiting & 10 & 20 \\
Painful injection site & 2 & 4 \\
Hypotension & 5 & 10 \\
High block & 2 & 4 \\
Difficulty in breathing & 0 & 0 \\
\hline
\end{tabular}

are shown in Table 2.

Clinical response to epidural steroid injection was graded as very good, good and poor. Very good relief was defined as complete resolution of presenting symptom. A good response was defined as $50-75 \%$ pain relief while no improvement/less than $50 \%$ pain relief was defined as a poor response to treatment. Pain relief was very good in 37 (74\%) patients while good response was seen in 9 (18\%) patients and no significant pain relief was seen in $4(8 \%)$ patients.

\section{DISCUSSION}

Pain due to disc protrusion is thought to arise from the release of arachidonic acid metabolites namely prostaglandin $E_{2}$, thromboxane, phospholipase $A_{2}$, tumour necrosis factor, and interleukin from herniated disc cells. Close proximity of herniated disc cells and nerve roots may sensitize the roots to pain [11]. A combined treatment modality including bed rest, physiotherapy and medications (analgesics and muscle relaxants) with epidural steroid injections provide a better outcome than any single modality used in isolation.

Use of epidural steroid injection for treatment of acute or chronic pain syndrome has its proponents [12-16]. The belief is that use of corticosteroid in these conditions helps decrease inflammation either by decreased synthesis or release of proinflammatory substances, as well as causing a reversible local anaesthetic effects. Addition of epidural tramadol has shown success in postoperative pain relief. Tramadol, being an atypical opioid, exerts its effect due to varied mechanisms such as mu receptor binding, inhibition of noradrenaline and serotonin reuptake $[17,18]$ in the spinal cord and local anaesthetic properties [19,20].

The available literature demonstrates moderate evidence that lumbar epidural steroid injections are effective in reducing pain in the short term and improving functional outcomes. The three approaches for lumbar epidural steroid injections, including transforaminal, caudal and interlaminar, are relatively safe with low reported complication rates. This combination of documented efficacy with a high safety margin justifies their frequent use. However, these generalizations of efficacy and safety cannot be extended to cervical transforaminal epidural steroid injections. Cervical injections most frequently performed by either a transforaminal or interlaminar approach confer a significant risk of potentially devastating complications [21-23].

Single shot epidural injection for treatment of cervical and lumbosaccral radiculopathy has not been previously reported; furthermore, to our knowledge, this is the first experience of such a technique been tried with good results. Previously, two separate injections for cervical and lumbar sciatica were given increasing the number of injections, thereby increasing the patients discomfort and financial burden. We thought to treat both problems in one injection by increasing the volume of medication and tilting the table 25 degrees, which would lead to drug ascension and pain relief.

The effect of patient position and level of epidural block has been studied by many groups [24-27]. Use of the lateral and trendelberg positions while administering the block, as well as keeping the affected side down, leads to better pain relief, faster onset and a higher level of anaesthetic block.

The success rate in our study was also encouraging, with pain relief in up to $92 \%$ of our patients. Use of drug combinations may have been partially responsible for good relief, along with corticosteroids for inflammation and tramadol for modulating the central pain reflex.

The limitations of our study were the small sample size and lack of a control group.

In conclusion, this technique provides good pain relief in patients with cervical and lumbosaccral radiculopathies for nonsurgical management of pain.

\section{REFERENCES}

1. Côté P, Cassidy JD, Carroll L. The Saskatchewan Health and Back Pain Survey. The prevalence of neck pain and related disability in Saskatchewan adults. Spine 1998; 23: 168998.

2. Bovim G, Schrader H, Sand T. Neck pain in the general population. Spine 1994; 19: 1307-9.

3. Linton SJ, Halldén K. Can we screen for problematic back 
pain? A screening questionnaire for predicting outcome in acute and subacute back pain. Clin J Pain 1998; 14: 209-15.

4. Radhakrishnan K, Litchy WJ, O'Fallon WM, Kurland LT. Epidemiology of cervical radiculopathy. A population-based study from Rochester, Minnesota, 1976 through 1990. Brain 1994; 117: 325-35.

5. Goebert HW Jr, Jallo SJ, Gardner WJ, Wasmuth CE. Painful radiculopathy treated with epidural injections of procaine and hydrocortisone acetate: results in 113 patients. Anesth Analg 1961; 40: 130-4.

6. Berman AT, Garbarino JL Jr, Fisher SM, Bosacco SJ. The effects of epidural injection of local anesthetics and corticosteroids on patients with lumbosciatic pain. Clin Orthop Relat Res 1984; 188: 144-51.

7. Catchlove RF, Braha R. The use of cervical epidural nerve blocks in the management of chronic head and neck pain. Can Anaesth Soc J 1984; 31: 188-91.

8. Pawl RP, Anderson W, Shulman M. Effect of epidural steroids in the cervical and lumbar region on surgical intervention for diskogenic spondylosis. In: Proceedings of the Fourth World Congress on Pain (Advances in Pain Research and Therapy). 9th ed. Edited by Cervero F. New York, Raven Press. 1985, pp 791-8.

9. Shulman M, Nimmagadda U, Valenta A. Cervical epidural steroid injection for pain of cervical spine origin. Anesthesiology 1984; 61: A223.

10. Malhotra G, Abbasi A, Rhee M. Complications of transforaminal cervical epidural steroid injections. Spine 2009; 34: $731-9$.

11. Raj PP. Intervertebral disc: anatomy-physiology-pathophysiology-treatment. Pain Pract 2008; 8: 18-44.

12. Koes BW, Scholten RJ, Mens JM, Bouter LM. Efficacy of epidural steroid injections for low-back pain and sciatica: a systematic review of randomized clinical trials. Pain 1995; 63: 279-88.

13. Koes BW, Scholten RJ, Mens JM, Bouter LM. Efficacy of spinal steroid injection for low back ache and sciatica: an updated systemic review of randomized control trial. Pain Digest 1999; 9: 241-7.

14. Bogduk N, McGuirk B. Monotherapy. In: Medical management of acute and chronic low back pain. 13th ed. Netherlands, Elsevier Science. 2002, pp 143-62.

15. Abdi S, Datta S, Lucas LF. Role of epidural steroids in the management of chronic spinal pain: a systematic review of effectiveness and complications. Pain Physician 2005; 8: 127-43.

16. Abdi S, Datta S, Trescot AM, Schultz DM, Adlaka R, Atluri SL, et al. Epidural steroids in the management of chronic spinal pain: a systematic review. Pain Physician 2007; 10: 185212.

17. Driessen B, Reimann W. Interaction of the central analgesic, tramadol, with the uptake and release of 5-hydroxytryptamine in the rat brain in vitro. Br J Pharmacol 1992; 105: 147-51.

18. Raffa RB, Friderichs E, Reimann W, Shank RP, Codd EE, Vaught JL. Opioid and non-opioid components independently contribute to the mechanism of action of tramadol, an 'atypical' opioid analgesic. J Pharmacol Exp Ther 1992; 260: 275-85.

19. Tsai YC, Chang PJ, Jou M. Direct tramadol application on sciatic nerve inhibits spinal somatosensory evoked potentials in rats. Anesth Analg 2001; 92: 1547-51.

20. Pang WW, Huang PY, Chang DP, Huang MH. The peripheral analgesic effect of tramadol in reducing propofol injection pain: a comparison with lidocaine. Reg Anesth Pain Med 1999; 24: 246-9.

21. Derby R, Lee SH, Kim BJ, Chen Y, Seo KS. Complications following cervical epidural steroid injections by expert interventionalists in 2003. Pain Physician 2004; 7: 445-9.

22. Botwin KP, Castellanos R, Rao S, Hanna AF, Torres-Ramos FM, Gruber RD, et al. Complications of fluoroscopically guided interlaminar cervical epidural injections. Arch Phys Med Rehabil 2003; 84: 627-33.

23. Scanlon GC, Moeller-Bertram T, Romanowsky SM, Wallace MS. Cervical transforaminal epidural steroid injections: more dangerous than we think? Spine 2007; 32: 1249-56.

24. Apostolou GA, Zarmakoupis PK, Mastrokostopoulos GT. Spread of epidural anesthesia and the lateral position. Anesth Analg 1981; 60: 584-6.

25. Makki D, Nawabi DH, Francis R, Hamed AR, Hussein AA. Is the outcome of caudal epidural injections affected by patient positioning? Spine 2010; 35: E687-90.

26. Setayesh AR, Kholdebarin AR, Moghadam MS, Setayesh HR. The trendelenburg position increases the spread and accelerates the onset of epidural anesthesia for cesarean section. Can J Anaesth 2001; 48: 890-3.

27. Coppejans HC, Hendrickx E, Goossens J, Vercauteren MP. The sitting versus right lateral position during combined spinal-epidural anesthesia for cesarean delivery: block characteristics and severity of hypotension. Anesth Analg 2006; 102: 243-7. 